\title{
What is Energy? Examining Engineering Students' Conceptions of Energy
}

\author{
Madeline Nelson, University of San Diego \\ Prof. Gordon D Hoople, University of San Diego
}

Dr. Gordon D. Hoople is an assistant professor and one of the founding faculty members of integrated engineering at the University of San Diego. He is passionate about creating engaging experiences for his students. His work is primarily focused on two areas: engineering education and design. Professor Hoople's engineering education research examines the ways in which novel approaches can lead to better student outcomes. He is the principal investigator on the National Science Foundation Grant "Reimagining Energy: Exploring Inclusive Practices for Teaching Energy Concepts to Undergraduate Engineering Majors." He has also co-developed a unique interdisciplinary course, Drones for Good, where engineering students partner with peace studies students to design a quadcopter that will have a positive impact on society.

\section{Dr. Joel Alejandro Mejia, University of San Diego}

Dr. Joel Alejandro (Alex) Mejia is an assistant professor of Integrated Engineering at the University of San Diego. His current research investigates how the integration of the historically and culturally accumulated wealth of knowledge, skills, and practices - also known as funds of knowledge - and engineering design can serve as a pathway to and through engineering. Dr. Mejia is particularly interested in how Latinx adolescents bring forth unique ways of knowing, doing, and being that provide them with particular ways of framing, approaching, and solving engineering problems. Dr. Mejia's primary research interests lie at the intersection of engineering education and social justice. He is particularly interested in the integration of Chicanx Cultural Studies frameworks and pedagogies in engineering education, and critical consciousness in engineering through social justice.

\section{Dr. Diana Chen, University of San Diego}

Dr. Diana A. Chen is an Assistant Professor of Integrated Engineering at the University of San Diego. She joined the Shiley-Marcos School of Engineering in 2016. Her research interests are in areas of sustainable design, including biomimicry and adaptability in structural, city, and regional applications. She earned her MS and PhD in Civil Engineering from Clemson University in South Carolina, and her BS in Engineering from Harvey Mudd College.

\section{Dr. Susan M Lord, University of San Diego}

Susan M. Lord received a B.S. from Cornell University in Materials Science and Electrical Engineering (EE) and the M.S. and Ph.D. in EE from Stanford University. She is currently Professor and Chair of Integrated Engineering at the University of San Diego. Her research focuses on the study and promotion of diversity in engineering including student pathways and inclusive teaching. She is Co-Director of the National Effective Teaching Institute (NETI). Her research has been sponsored by the National Science Foundation (NSF). Dr. Lord is among the first to study Latinos in engineering and coauthored The Borderlands of Education: Latinas in Engineering. Dr. Lord is a Fellow of the IEEE and ASEE and is active in the engineering education community including serving as General Co-Chair of the Frontiers in Education Conference, President of the IEEE Education Society, and Associate Editor of the IEEE Transactions on Education (ToE) and the Journal of Engineering Education (JEE). She and her coauthors received the 2011 Wickenden Award for the best paper in JEE and the 2011 and 2015 Best Paper Awards for the IEEE ToE. In Spring 2012, Dr. Lord spent a sabbatical at Southeast University in Nanjing, China teaching and doing research. She is on the USD team implementing "Developing Changemaking Engineers", an NSF-sponsored Revolutionizing Engineering Education (RED) project. Dr. Lord is the 2018 recipient of the IEEE Undergraduate Teaching Award. 


\title{
What is Energy? Examining Engineering Students' Conceptions of Energy
}

\begin{abstract}
Public opinion about energy issues has created an ideological divide between renewable and non-renewable energy sources. In engineering education, energy concepts are sometimes divided and analyzed by disciplinary boundary lines. In an effort to explore how to better teach energy concepts to our students, we sought to first understand how students conceptualize energy. This paper outlines a survey that was administered to students at a small, private, western school of engineering to gain insight into students' understanding of energy concepts and issues $(n=82)$. The survey consisted of questions to gauge students' interests in energy, existing technical understanding, and energy tendencies. The data collected from the survey was used to create and tailor a new energy class to the students so the concepts can be built around student interest and embodied knowledge.
\end{abstract}

\section{Introduction}

Energy is a fundamental concept that is commonly taught in foundational engineering classes in the "middle years" where students often struggle to find relevance [1], [2]. Instructors deliver lectures on the processing, production, storage and delivery of energy for industrial and household purposes. There are discussions about the resources used to create energy and how to better use those resources. Sometimes engineering considerations of energy focus on quantities and numbers involving efficiency and costs. Energy continues to be one of those engineering topics that is siloed and discussed in isolation without a social, cultural, or environmental context.

The conceptualization of energy within a sociotechnical framework is critical for the formation of future engineers if they are to address the energy issues of the world. This paper describes an exploratory analysis of undergraduate engineering students' conceptions of energy. The study is part of a larger investigation around the ways in which students respond to new integrated approaches to energy (i.e., a disentanglement of the usage of the word "energy" across disciplines) in the engineering curriculum. We are in the process of launching a new course, Integrated Approach to Energy, that will be our students' first formal introduction to energy in a recently launched interdisciplinary engineering major.

To better meet our students where they are, we wanted to understand how they conceptualize energy broadly from their own educational experiences and embodied knowledge. As instructors we have noticed that many students, even after taking multiple courses related to energy throughout their college career, still do not have a broad understanding of energy related concepts and its significance in solving sociotechnical problems. One of the challenges we have observed is that students often lack a cohesive definition for energy. Energy concepts are often taught to students in ways that do not connect to their lived experience. Many students do not 
have a way to relate personally to the subject, and thus struggle to see how these concepts are relevant to either their personal lives or their future work as an engineer.

In this paper, we will begin with a short literature review on energy education followed by an overview of the context in which this study took place. We then present an analysis of the survey data we collected that examines how students at our university conceptualize energy.

\section{Literature Review}

The current body of literature in energy education explores not only the pedagogical aspects, but also the nature of energy education. Energy is a foundational concept and is taught in many different contexts, both within engineering and more broadly in Science, Technology, Engineering, and Math (STEM). As we reviewed this literature, three major questions emerged: how do we define energy? (ontology), how do students conceptualize energy? (epistemology), and how do we teach energy? (pedagogy).

\section{An Ontological Question: How do we define energy?}

Energy is a relatively hard concept to define. Many students first see energy defined in physics as "the ability to do work" [3]. Various other definitions have been proposed over the years. Lancor had students create analogies to describe different energy topics and found that using a metaphorical lens allowed the students to better conceptualize the idea [4]. Hecht proposed a definition based on change, focusing on the idea of Conservation of Energy, and emphasized that energy is transformed into different forms to be used differently [5]. Kapper et al., on the other hand, critiqued the use of "forms of energy" as a manner of teaching the concept because, among a litany of reasons, they believed that such an approach tended to emphasize only kinetic and potential energy [6]. In the end we found Lehrman's definition, or lack thereof, to be the most useful. In his 1973 paper Energy is not the ability to do work he argues for embracing ambiguity, "Conservation of energy seems to be a natural law; the description of this law by means of a set of algebraic formulas is a human invention... If it is not possible to write a satisfactory definition in a few words, we will have to learn to get along without any such a neat package" [3, p. 18].

\section{An Epistemological Question: How do students conceptualize energy?}

Perhaps due to the complexity of defining energy using one single interpretation, students exhibit a wide range of misconceptions around energy [7]-[10]. An excellent study by Prince et al. examined several common misconceptions of engineering students including the difference between temperature and energy, temperature and the perception of hot and cold, and the amount of heat transfer versus the factors that affect the rate. Disappointingly, they found that students only scored marginally better on concept inventory questions designed to probe these misconceptions even after a semester of instruction on the topic. They found that these misconceptions stemmed primarily from two issues: not knowing what category of energy to focus on and lacking actual knowledge in that category [7]. 
Hadfield et al. examined students who had completed an introductory physics class that extensively covered thermodynamic concepts. They found, like Prince, that the students still had many misconceptions surrounding the fundamentals of thermodynamics, including the first law, heat, work, and energy [8]. Jewett published a series of five papers discussing how students come to be so confused around the idea of energy [9], [11]-[13], arguing that students cannot relate to the material and thus cannot make the connection of energy concepts to the real world. This divide between the theoretical and the practical was echoed by Solomon, where the key issue in their energy education study was the inability for students to relate the topics they are learning about to the real world. They found that students tended to think in two domains: everyday notions and scientific explanations. Students consistently did better on questions that related to everyday life but struggled to answer questions that forced them to draw on their theoretical knowledge of energy [10].

\section{A Pedagogical Question: How do we teach energy?}

The approaches taken by different educators to teaching energy vary greatly. Most traditional engineering curricula contain two courses directly related to energy - thermodynamics and circuits; however, these courses are rarely put in conversation with one another. There have been some efforts to teach energy in a more integrated fashion. Trumper et al. proposed using a constructivist approach where they leverage students' prior knowledge about energy and use it to make connections and co-construct a more holistic definition [14], [15]. They emphasize that the primary benefit of this approach is that students develop a definition for energy that they personally understand. Choudhury et al. describe a similar constructivist approach; however instead of occurring during a single semester, the process occurs over the course of the entire engineering curriculum, starting with students' first year in college [16]. This focus on energy was achieved mainly through lab-based classes in which students had the opportunity to gain hands-on experience with energy concepts, again responding to the need for helping students connect theory and practice. Kapper et al. proposed a literacy-based solution that used "intermediary language" to relate the complex theoretical energy concepts to college students' prior knowledge and experiences [6]. This approach recognized that many student misconceptions come from the different ways in which engineers and laypeople use terms like heat and work. They found that by introducing intermediary language they could help students seamlessly transition to a place of engineering literacy. These more integrated approaches have informed our new course and we intend to use a constructivist approach to help students develop their own definition of energy.

\section{Context}

The results from our survey are being used to inform a new course that is being offered in Spring 2020. Students will take this course in their second year as engineering students. Our overall project seeks to incorporate practices from culturally-sustaining pedagogies (CSPs), a collection 
of pedagogical approaches that take a critical eye towards linguistic, literate, social and cultural hegemony. We seek to learn from CSPs to create a classroom where students learn to acknowledge the differing values and perspectives of others, particularly those related to energy. One core tenet of CSPs is to recognize students' lived experiences and personal funds of knowledge. CSPs will be used to illustrate energy concepts and issues to the students to allow them to understand and relate to energy in a deeper manner than a purely technical thermodynamics course would allow. This course is part of a new major that aims to give students a strong technical foundation across multiple areas of engineering, while at the same time encouraging them to recognize the impact engineers have on society. This major prepares students to tackle society's most complex challenges by emphasizing the sociotechnical nature of problems. The interdisciplinary nature of the major allows students to pursue courses that give them subject matter expertise in their area of interest. Based on this review, we have designed our course to try and connect theoretical energy content directly with students lived experiences. We hope that by focusing on making these connections explicit for the students, we can overcome some of these common misconceptions.

\section{Methods}

With a foundational understanding of students' conceptions of energy grounded in the literature, we developed a survey to examine the specific energy knowledge of our students. The survey was adapted from an energy literacy survey created by Dr. Jan DeWaters that has been used in multiple contexts, including both K-12 and higher education [17], [18]. Her original survey was designed to gauge energy literacy which encompasses students' energy-related knowledge, attitudes, and intentions/behaviors [17]. The original survey examined four categories relating to students' understanding of energy: cognitive, affective, self-efficacy, and behavior. The students scored lowest on the cognitive questions, but they were aware of many of the issues surrounding energy and the need for conservation. We selected a total of 43 questions that focused on three primary areas: students' interest in energy topics, students' pre-existing factual knowledge about energy, and students' attitudes towards energy policy issues. We are willing to distribute the full text of the survey, please email us if interested.

This online survey was distributed via email to students enrolled in both the Introduction to Engineering course (first-year students, $n=36$, response rate $\sim 75 \%$ ) and Capstone Design (senior students, $n=46$, response rate $\sim 50 \%$ ) at the end of the semester. The survey captured a reasonable representation of the demographics at the university in question on both gender (35\% women) and race (47\% White, 20\% Asian or Pacific Islander, 14\% Latinx, 11\% multiple races, and 8\% Middle Eastern or North African). We also had a broad distribution of engineering majors respond to the survey. (Note that most first-year students had not yet declared a specific major.) We received all appropriate approvals from our university IRB. 
Survey data was analyzed in several ways. For questions related to students' interest in energy topics, we generated plots (similar to Figure 1) to quickly review the data. The most interesting result observed from this initial pass was related to students' differences in interest between renewable energy and fossil fuels. Students ranked their interest (not at all interested to very interested) in the following sources of energy on the scale shown in Figure 1: natural gas, hydroelectric, solar, wind, nuclear, coal, and petroleum. This data is presented in its raw form in Figures 1 and 2. We noticed a trend in the data between renewable energy and fossil fuels with students being more interested in renewable energy. We therefore created a composite score based on weighted factors by aggregating students' responses to the Likert questions [19]. The fossil fuel score was computed from coal, petroleum, and natural gas while the renewables score was developed from the questions on solar, wind, and hydroelectric. (Nuclear was not included in either category.) We computed a student's $t$-test between all means using $\mathrm{p}<0.01$ as the threshold for a statistically significant difference [20].

For factual questions related to students' energy knowledge, we calculated the percentage of students that answered the questions correctly. For students' attitudes towards energy policy, we performed emergent thematic coding of students' open responses to the question, "What is your greatest concern about the future of energy?"

\section{Results}

Students' Interest in Energy-Related Topics

We asked a series of questions to gauge students' interest in energy related topics. The most interesting result from these questions was in response to the question "What sources of energy are you interested in learning more about?" Figures 1 and 2 present the raw data, while Figure 3 and Table 1 present composite scores for renewable energy and fossil fuels (see Methods section). Note that for Figure 3 we found statistically significant differences $(p<<0.01)$ in all cases except when comparing first-years' and seniors' interest in renewables. First-year students were more interested in learning about renewable energies than fossil fuels, though they showed substantial interest in both groups (Figure 1 and 3). For seniors, the desire to learn about renewable energies was just as strong as the first-year students (no statistical difference in the composite score), however their interest in fossil fuels is considerably lower than that of firstyear students (Figure 2 and 3 ). This result is not surprising - our curriculum currently emphasizes fossil fuel based energy with only a few elective courses about renewables. We interpret this data to indicate that students come in hoping to learn about renewable energy in their engineering curriculum and this interest is currently not being met by their courses.

We also asked students to indicate what areas of consumption they were interested in learning about (transportation, manufacturing, residential, and commercial). The data suggests students' interest in these topics is high ( $>70 \%$ somewhat or very interested), though no area is substantially more interesting than others. Students also showed a high level of interest in 
contemporary global challenges related to energy ( $>80 \%$ somewhat or very interested). Based on these findings we plan to include substantial renewable energy content as well as information about global energy challenges in our new course.

\section{First-Year Students}

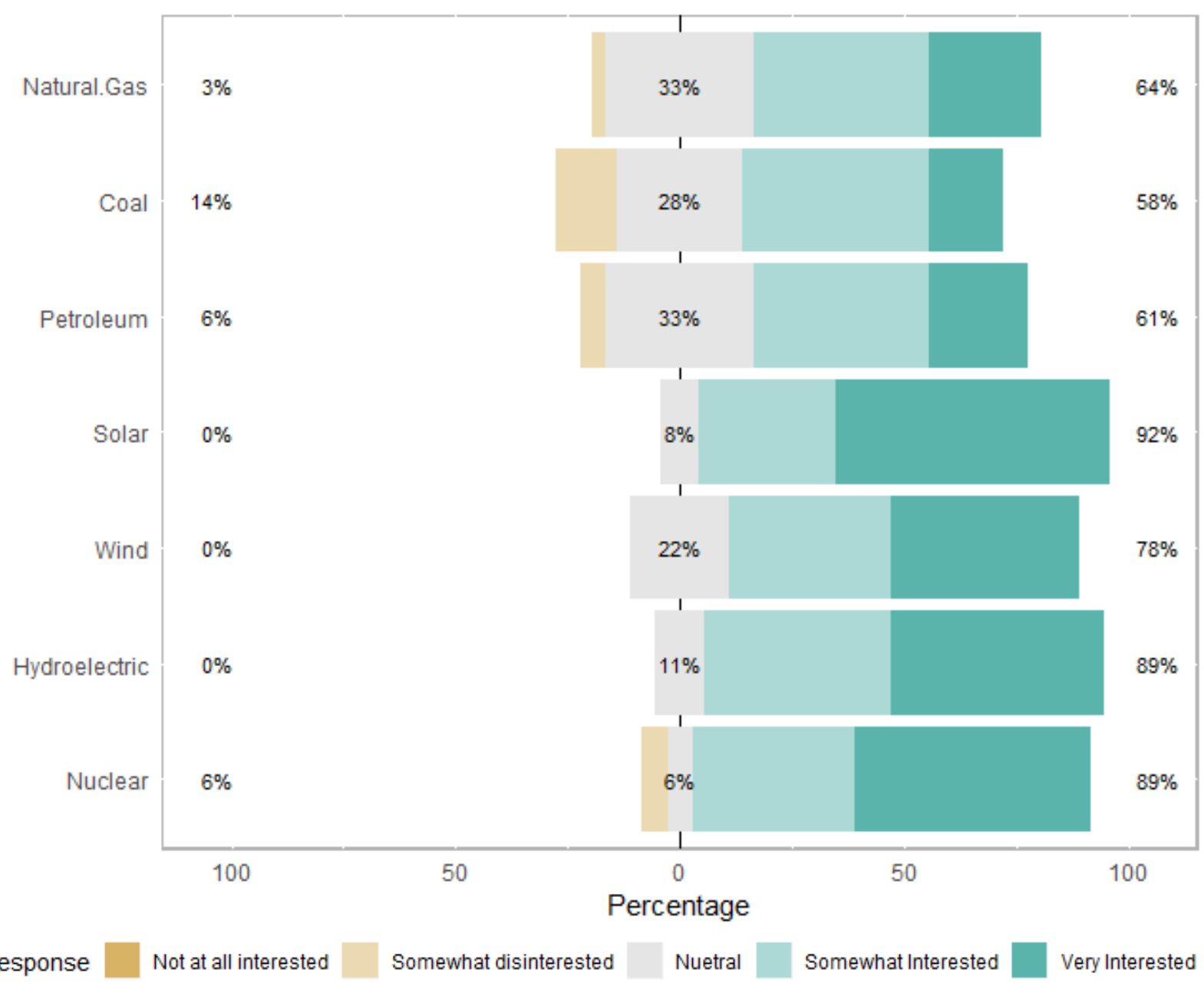

Figure 1. First-year student responses $(n=36)$ to the question "What sources of energy are you interested in learning more about?" Percentages reflect an aggregate of responses in three categories: not at all/ somewhat disinterested, neutral, and somewhat/very interested. 


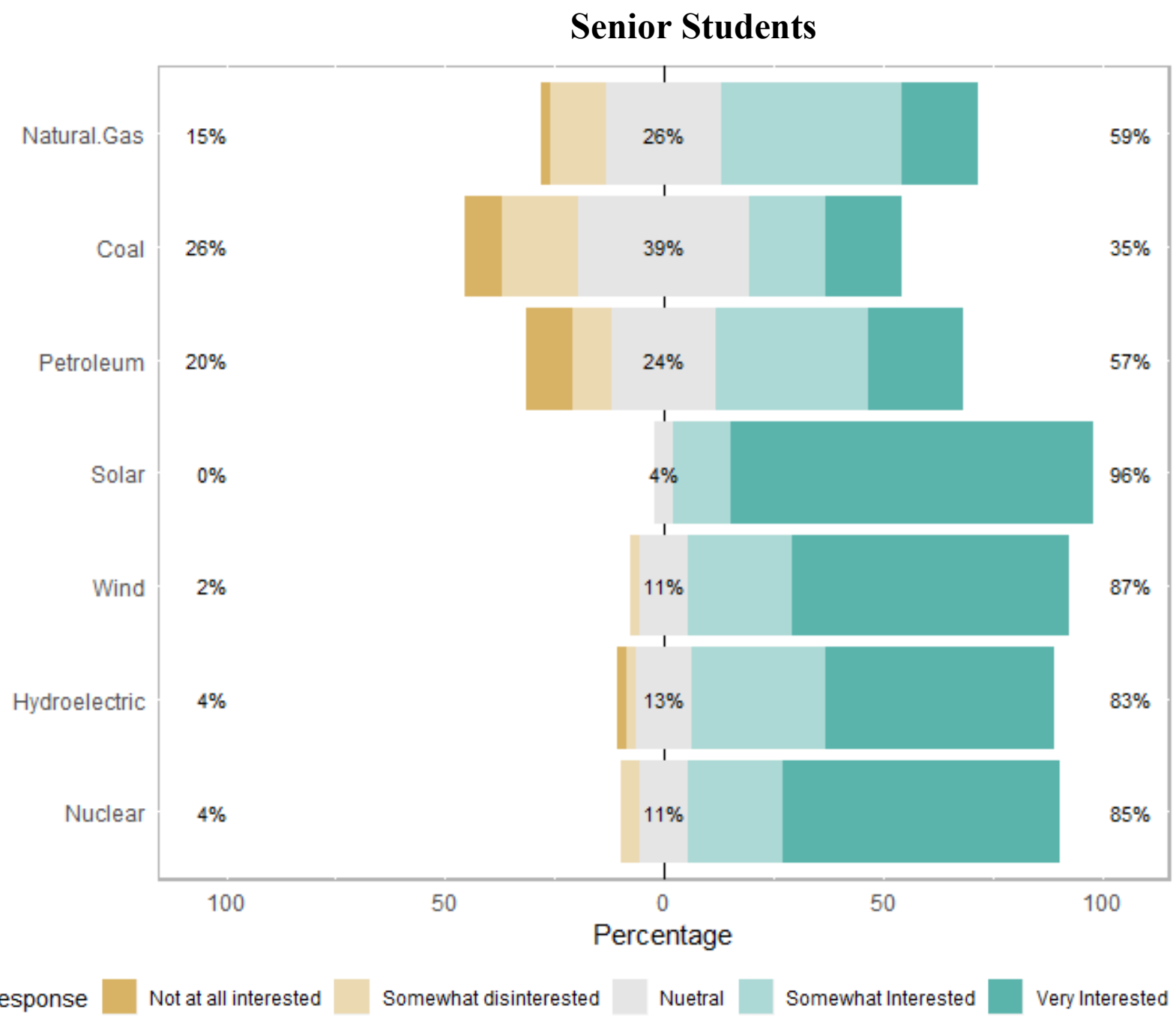

Figure 2. Senior student responses $(n=46)$ to the question "What sources of energy are you interested in learning more about?" Percentages reflect an aggregate of responses in three categories: not at all/somewhat disinterested, neutral, and somewhat/very interested. 


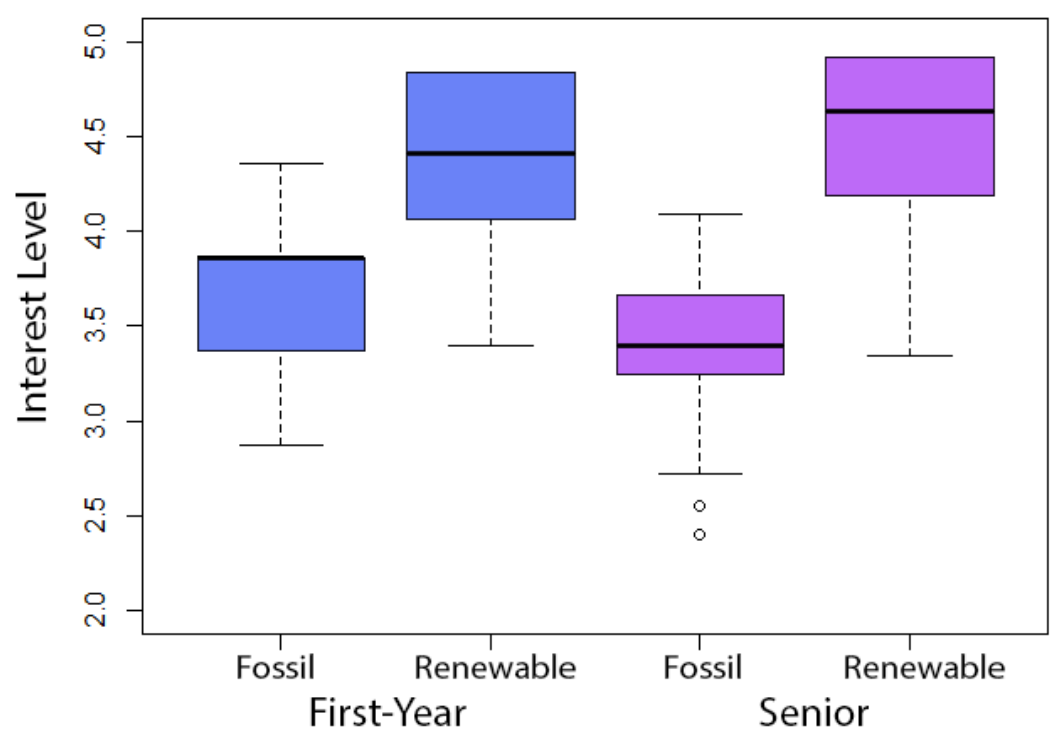

Figure 3. A box-and-whisker plot illustrating composite scores indicating student interest in fossil fuels and renewable energy. A score of 5 corresponds to very interested, while a score of 2.5 aligns with neutral. (The box encompasses the median of the first quartile to the median of the third quartile of data, the solid line represents the median of the full dataset, the whiskers extend to the minimum and maximum values in the set after removing outliers, and open circles represent outliers.)

Table 1. Composite scores showing student interest in fossil and renewable energy. All means found to be statistically different (t-test, $\mathrm{p}$-value $<<0.01$ ) with the exception of first-year and senior interest in renewables.

\section{Fossil Fuels Renewables}

\begin{tabular}{lcccc} 
& Mean & $\sigma$ & Mean & $\sigma$ \\
\hline First-year & 3.8 & 0.4 & 4.4 & 0.4 \\
Seniors & 3.4 & 0.4 & 4.5 & 0.5
\end{tabular}

\section{Students' Factual Knowledge About Energy}

We asked students a range of questions that tested their factual knowledge about energy, such as "The amount of electricity we use is measured in units called?" with unit choices of $\mathrm{kW}, \mathrm{kW}-\mathrm{h}$, BTU, Volts, and Horsepower. Seniors answered these questions correctly at higher rates than first-year students, which was expected, as many of these questions involved content that had 
been covered in their previous courses. For instance, $74 \%$ of the seniors answered the question above correctly as compared to $28 \%$ of the first-year students.

This section of the survey also contained some factual questions about contemporary energy issues. For example, one of the questions included was "Which of the following resource provides most of the energy used in the US each year?" Students' responses showed a higher level of inaccuracy on these questions, with relatively small differences between seniors and first-year students. For instance, $48 \%$ of seniors answered the question above correctly compared to only $37 \%$ of first-years. We did not find these trends particularly surprising; our current curriculum focuses primarily on technical content related to energy (e.g., units) and tends not to discuss contemporary energy issues. These findings, combined with students' self-reported interest in these topics, make a strong case for including more discussions of contemporary energy issues in introductory energy courses.

\section{Students' Attitudes Towards Energy Policy Issues}

In the last set of questions, we examined students' attitudes towards different proposed energy policies. For example, we asked students to rate their agreement using a Likert scale to statements like "More wind farms should be built to generate electricity, even if the wind farms are located in scenic valleys, farmlands, and wildfire areas." The students' answers to these questions revealed an interesting opportunity for student engagement - there was not widespread agreement on the best path forward for energy policy. These differences of opinion could be used to engage students in meaningful discussions about the trade-offs associated with our energy future.

We also asked students in an optional free response question "What is your greatest concern about the future of energy?" to which $85 \%$ of students responded. Several consistent themes emerged from this data. For example, $15 \%$ of these respondents indicated they were afraid that society is too reliant on fossil fuels, with comments such as "How dependent we are on coal and petroleum". In addition, $10 \%$ also indicated concern that, not only will fossil fuels run out, but that their usage has already caused irreversible damage to the environment (e.g., "Irreparable damage to the global climate/environment"). Another major theme (10\%) was that society should move towards more renewable energy sources. One student answered, "That we continue to use unhealthy energy resources instead of switching completely to the use of renewable energy." Students also revealed a nuanced understanding of the challenges facing society: $13 \%$ shared a concern that there is no manner of producing energy that will cause no harm to the environment and the best we can hope for is to find a solution that causes the least amount of damage. One student responded, "Being able to efficiently produce renewables in a way that is harmonious with the environment". We were impressed with the nuanced views presented by students in response to these questions. 


\section{Conclusion}

Energy is an incredibly challenging topic with technical and social elements that cannot be disentangled. While there is high quality research investigating how to teach energy more effectively, engineering curricula have been slow to change. This is likely due to many factors such as energy being part of the "middle years" where inflexible canons exists, energy is hard to define, students have pernicious misconceptions, or because energy is such a broad topic that faculty feel they have insufficient expertise to cover it broadly and prefer to remain in their disciplinary silos. Nonetheless, as evidenced by our survey data, current students are interested in this topic. They want to learn more about energy, particularly renewables, as well as develop a better understanding of global policy issues related to energy. It is important for engineering educators to respond to the current needs of our students and move beyond how we were taught to help prepare students for the challenges of today. We argue that knowledge and skills related to renewable energy should be incorporated in the "middle years" and throughout the engineering curriculum with fossil fuels moving to a lower priority or elective status. We hope that our new class will help to better meet students' expectations and serve as an example for others of an integrated approach to this topic. As one student said in our survey, "The issue of how to sustainably produce energy is one of the biggest and most complex that my generation will have to deal with." We could not agree more.

\section{Acknowledgements}

The authors would like to thank Dr. Jan Dewaters for help in adapting her survey. Partial support for this work was provided by the USA National Science Foundation's Improving Undergraduate STEM Education (IUSE) program under Award No. 1836504. Any opinions, findings, and conclusions or recommendations expressed in this material are those of the authors and do not necessarily reflect the views of the National Science Foundation.

\section{References}

[1] S. M. Lord and J. C. Chen, "Curriculum design in the middle years," in Cambridge Handbook of Engineering Education Research (CHEER), B. Olds and A. Johri, Eds. Cambridge University Press, 2015, pp. 181-200.

[2] J. C. Lucena and J. A. Leydens, "From Sacred Cow to Dairy Cow: Challenges and Opportunities in Integrating of Social Justice in Engineering Science Courses," in ASEE Annual Conference Proceedings, 2015.

[3] R. L. Lehrman, "Energy Is Not The Ability To Do Work," Phys. Teach., 1973.

[4] R. A. Lancor, "Using Student-Generated Analogies to Investigate Conceptions of Energy: A multidisciplinary study," Int. J. Sci. Educ., vol. 36, no. 1, pp. 1-23, 2014.

[5] E. Hecht, "Energy and Change," Am. Assoc. Phys. Teach., vol. 45, no. 2, 1970.

[6] W. H. Kapper and M. J. Goedhart, "Forms of Energy', an Intermediary Language on the Road to Thermodynamics? Part II," Taylor Fr. Int. J. Sci. Educ., vol. 24, no. 2, pp. 119137, 2010.

[7] M. J. Prince, M. A. Vigeant, and K. E. K. Nottis, "Development of the Heat and Energy Concept Inventory: Preliminary Results on the Prevalence and Persistence of Engineering 
Students' Misconceptions," J. Eng. Educ., vol. 101, no. 3, pp. 412-438, 2012.

[8] L. C. Hadfield and C. E. Weiman, "Student Interpretations of Equations Related to the First Law of Thermodynamics.," J. Chem. Educ., 2010.

[9] J. Jewett, "Energy and the Confused Student I: Work," Phys. Teach., vol. 46, 2008.

[10] J. Solomon, "Learning About Energy: How Pupils Think Tn Two Domains," Eur. J. Sci. Educ., vol. 5, pp. 49-59, 1983.

[11] J. Jewett, "Energy and the confused student II," Phys. Teach., vol. 46, 2008.

[12] J. Jewett, "Energy and the confused student III," Phys. Teach., vol. 46, 2008.

[13] J. Jewett, "Energy and the confused student IV: A global approach to energy," Phys. Teach., vol. 46, 2008.

[14] R. Trumper, "Energy and a constructivist way of teaching," Phys. Educ., 1990.

[15] R. Trumper, "Being constructive: An alternative approach to the teaching of the energy concept-part two," Int. J. Sci. Educ., 1991.

[16] A. Choudhury, J. Rodriguez, P. Ikonomov, J. M. Mydosh, and J. M. Shane, "Energy Efficiency in Engineering Design Curriculum Paper," in ASEE Annual Conference and Exposition, 2011.

[17] J. DeWaters, S. Powers, and M. Graham, "Developing an energy literacy scale," in ASEE Annual Conference and Exposition, Conference Proceedings, 2007.

[18] C. Mei-Shiu and D. Jan, "Development and Validation of the Energy-Issue Attitude Questionnaire: Relations with Energy Knowledge, Affect, and Behavior," J. Adv. Educ. Res., 2018.

[19] J. Starkweather, "How to Calculate Empirically Derived Composite or Indicator Scores," 2012. [Online]. Available: https://it.unt.edu/sites/default/files/compositescores_jds_feb2012.pdf.

[20] G. Norman, "Likert scales, levels of measurement and the 'laws' of statistics," Adv. Heal. Sci. Educ., vol. 15, no. 5, pp. 625-632, 2010. 